\title{
Preparation of Electronic Dynamic Cards on Potential Erossian Damage of Electric Power Plants on Gas Technology
}

\author{
ZH Aliyev* \\ Institute of Erosion and Irrigation of ANAS, Baku, Azerbaijan
}

*Corresponding author: RAHS ZH Aliyev, Institute of Erosion and Irrigation of ANAS, Baku, Azerbaijan.

Received Date: August 20, 2019

Published Date: August 30, 2019

\section{Annotation}

The fact that the state and folk sensitivity of a well-known research work carried out by us as one of the main participants of the multi-field projects implemented within the scientific-technical assistance program for the development of the agrarian sector in Azerbaijan has been proven scientifically based on the level of agricultural land availability in the country. Their diverse range of electron land-erosion maps is being developed and implemented with the application of the application of scientific recommendations for the region's natural-historical-economical and other features, and for the stabilization of the current situation in each region. designed for the selected research area in Azerbaijan for the creation of a map of the Eurasian threat hazard and the database was developed. Various sizes of today's proposed electronic maps have been developed and approved by the following technical specifications and rich technical guidelines. All constructor-technological, cartographic, contrasting image documents for this purpose, and so on. The geographical-social and hydrogeological-economic, geographical-geographical and economic-geographicalgeographical-geographical-geographical observations accompanied by rich and accurate topographical measurements of the information reflecting the placement, position and connection of various natural and social phenomena here, were transferred to the surface of the ground surface on the boundary line of the first Agsu region and the application of scientifically-applied recommendations to improve its properties. In this regard, the field and laboratory investigations are being conducted to determine the erosion process and the intensiveness of the erosion observed in the area, where it has been preferred to explore the well-known areas by natural geographical, stationary and semi-stationary methods [1-5].

Keywords: Orthogonal; Image visual; Red spectrum; Erosion; Aerospace images; Satellite imagery; Pixel

\section{Introduction}

After reaching independence in Azerbaijan, the development of agriculture is of great importance in raising the national economy. However, one of the main factors that hinders the development of agricultural crops, the stable and high yield from it is the erosion of the soil.The severity of the erosion process leads to the loss of soil fertility, the reduction of water resources and degradation of the soil cover. The decentralization of the important challenges facing the country in the development of agriculture is directly related to all other factors, including anti-erosion measures.This problem is of particular importance for the republic's conditions. Thus, in large districts of Azerbaijan, water, wind, irrigation, surface spread, landslide, flood and other types of erosion have been created each year, resulting in the loss of soil, which is the main means of production in agriculture, its fertility, causing washing loss. This, in turn, significantly reduces the productivity of agricultural plants and adversely affects the quality of the product.

The development of the erosion process results in a decline of useful land. Such lands are transformed into unproductive soils from the agricultural cycle. It should be noted that, according to estimates, currently $43.3 \%$ of the country's land fund, and $80-90 \%$ in some regions constitute eroded lands. In this regard, for the known purpose, the development of erosion hazard maps of the territory of the country, it is characteristic of its relevance.

\section{Assignment and Execution of Research}

Ordering and delivery of raw materials for remote sensing analysis. Our research for selected multi-polar exploration studies is based on contemporary satellite imagery information. For this 
purpose, our scientific knowledge on satellite imagery is based on two selected sources of literature. Its choice criterion is a highresolution screen (compared to resolution of spatial photographs) with high-frequency data, the sensors to access data in eight spectral bands, and settings [5-8].

\section{The course of research}

Dynamics of the climate and the soil profile of the natural climate. The Aghsu period of aridation is accompanied by an analysis of the collection of materials based on the planned searches in July-September 2011. On the 18th of August 2012, two satellites were purchased on the western part of the area with four spectral lanterns (blue, green, red, yellow, NIR1, NIR2, Red Edge, Sahil Blue) recorded in the eastern part - 8 channels, green, red, NIR1). The ordered images (aerofotoscopes) spectral bandwidths have the ability to analyze multidimensional data for classification, which is intended to be used for this purpose. As a result, the data is transmitted through the geotif in the format of ortho-phoform, which satisfies the research assignments.

A channel exploration area, along the river coast, is described by blue color wavelength, confirming that chlorophyll is absorbed by healthy plants by $400-450 \mathrm{~mm}$. Therefore, this channel is considered acceptable for plant analysis. At the same time, this wave absorbs water in small biometric measurement studies, making them efficient. The beneficial feature of atmospheric dispersion is that it is essential for the radiometric effects of the atmosphere. The channel is effective in demonstrating that the Blue Canal (Blue) chlorophyll is absorbed by plants with a wave of 450-510 nm when the water skewer opener is less responsive to atmospheric exposure compared to the Coastal Blue. The Green Canal (Green) with another wavelength of $510-580 \mathrm{~mm}$ is used as a basis for assessing plant state along with the use of the yellow canal for plant species. A wavelength of 630-690 nm is recommended for Yellow Canal (Yellow) plant identification. Used in the study of the Red Canal (Red) plant - the red spectrum indicates that chlorophylline is swallowed by healthy plants. It is also used for the classification of soils, geological processes and roads. A red edge rising canal with a spectral solution wave of 705-745 mm is used throughout the season's largest screen, the fact that the plant species and their health classification.

Channel NIR1 (770-895 nm) is useful for moisture and biomass assessment, as well as separation of water bodies and separation of soil and plant communities.

Channel NIR2 (860-1040 $\mathrm{nm}$ ) has been recommended for plant studies and is less resistant to atmospheric impact than NIR1.

\section{Images (with pictures) Temporary classification}

Automatic pixel classification: The purpose of the pre-primary cultivation was to select vegetation degraded areas and to study soil cover. So, in order to be able to obtain direct information on the soil cover, it is possible to examine unnecessary parts. The ERDAS program, which is called the Imagery program with the purpose of Analysis 9.2, has been used for automatic pixel classification. The area of $150 \mathrm{~km}^{2}$ is used in two images World Viev-2, each with four and eight channels (300 $\mathrm{km}^{2}$ total). The pictures were balanced in the form of four-image of tonally smozaikovany: blue, green, red, NIR1.The classification of automatic classification shows that one parameter was implemented with different indicators (prices). In the process of coding parameters, Signatures has created a table with a slot. Image is divided into two classes based on visual (visual) analysis. Plant degraded area - Includes a group of plants, other areas covered. According to the classification, the profile of the first and second group images was changed to transparency in the two profile derivatives, plant degradation and surrounding (adjacent) coverage areas. Each card with derivatives grouped classes according to values similar to the four channels with spectral aggregation coefficients [8-12].

For this purpose, there are many histograms for the grades listed in the table. The group has 8 groups of plant deprived of 13 classes (2 lessons were non-generic). 7 classes and 6 groups of plant groups ( 5 classes were non-generic) were created. It works as much as possible for the sub-class, one color is assigned: 1) the color is similar to the similarity of spectral features, and 2) the color is in contrast between groups in CIR, 3). For example, dense plants in red color.

Despite their efforts, however, it did not know at the same time to provide three of the above criteria. The ability to combine two cards in one composition of the classic card color scheme is selected. Using Different Values of

Transparency: A card can be connected to a card with $\{0,1\}$ card.

An automatic signature has been added to the signature automatically, with the signature, swamps (4 signatures) and open water ( 8 signatures) created in the automatic classification process. Created, so there are two additional sub-signatures, swamps and water. This subcategory is bound to a group with no plant. Accordingly, the four-channel image classification, which was held at the sign-table table, was under control of World View2.

4 Classification of boundary restrictive territorial units: With visual visible soil cover (two pieces) - the initial classification of the object is compact vegetation and selection of space units (such segments are called) with existing segment segments. The basis for the classification of visualization of objects in terms of elimination of parameters and boundary values, which allows certain categories and a classification. The choice of optimal features of using this method is done by testing a selection of homogeneous parts of the image. Then, border values have been set to a certain frame for each category. What sets border values to belong to a particular category and sets boundary values to objects that have been completely removed. In this context, a homogeneous collection of visual properties is created in a way that has been allocated to them on the basis of the object. Based on the usage settings we agree with the result. Objects of each category have similarity to homogeneity and individual characteristics [12-17]. 
Field exploration and preparation of key photocopying: Investigations are pre-defined or taken around them (four soils) and additives are selected on the basis of variety of soil, soil or irrigation area.The research provisions were recorded using CIS / CPS. All items cover / use and landscape (view / agricultural crops, depth of field, salt on the surface, availability of solelyubnoy plant) collected information about selected features. Photo notes on items were made [17-21].The main exploration areas were dug up to shallow slopes at $50 \mathrm{~cm}$ (high density of soil due to its large depth).The purpose of desertification is to evaluate the aggregate composition of the upper part of soil moisture and soil composition and the development of photo documents on the profile.The rainfall, intensity and duration observed in Agsu in 2011 made it difficult to implement all the tasks. Generally, it is based on the collected material based on photo-interpreting suggestions, with 35 points.

\section{Analysis of Laboratory Research Results in the Context of Land Map Archive Structural Subdivisions}

The soil survey results of 100 balls are shown below.

Soil map archives have been designed to scale up a range of 1: 50000 of suitable soil types. Lack of compatibility is a complete outcome of the work, and in the case of gray grass, grass-grass soils are expected to change in the process of land acquisition under the influence of land use.

It is understood that there is a necessity of corrections to the soil contour on the opposite side of the research ground, where many grass-grass soils are created to create a compact and durable zone, in the north-eastern part of it. However, this typical grassgrass gives a small part of the light soil. Additionally, it is known from the more detailed study of the area that the grass gray soils in the southern part should be characterized. We need to create more compact areas for these lands. This site should have many small gray-grass and grass-gray soils. Gray-brown grass soils spread across the research object are rarely seen in the central part of the area. The purpose of research in just a few areas is not to create common and compact areas here. It should be noted that by referring to the materials collected, we find that landscape involvement is probably related to smaller ranges. In the center of the research object, some types of soil have been attributed to the absence of small and numerous gray soils in all research areas.

\section{Creation of test area algorithms for soil classification}

The study of the land cover types and their similarity to other morphological features and their types of soil are characterized by their relative integrity. These two factors are automatically reflected in the object classification based on satellite images of automatic pixel classification and first image segmentation (segmentation of images). The object classification is carried out on the basis of the results of our research in the field of practice in 2012. It has been selected from the pre-existing land and registered as land grass, grass-grass-gray, gray-grass-gray and grass-gray-light and wetgrass soils.
The second classification algorithm considers the following:

Classification of living points, water objects, streams and elements of transport infrastructure Exceptions organizes, illustrates,

The classification process is characterized by the characterization of the land cover (open soil) and the interval symptoms associated with a particular land use.

- Classification of soil types of nearby neighborhood utilization

Learn how to use the classification of test algorithms (intervals) determined for the next phase of the development of a land-landscape type of certain algorithm, soil types is aimed at. An automated test method was developed to determine the type of thematic layers of the cellular segmentation of the multicolored ground. Thus, there has been some classification for the future development of a range of parameters. In this case, the method of use is based on the classification of each individual soil class. This study describes the following examples of objects that are examples of those classes:

Among the features acquired on the basis of experiences with individual drawing images of the objects, there is a discrepancy. It should be noted that these findings are in need of unique materials in terms of visual characteristics. To do this, the polygon test performs identification by hand [21-25].

Class hierarchy created in real-time - the new class has created an image (drawing image) for each piece with unique features. Class (class) name is determined dependent on the visual properties of the objects.

The territory of the classification area covers 20 hectares. Cultivated fields, cotton fields, wheat, meadow, wetlands, deserts, forests and bushes, etc. contane. This coating structure consists of:

The largest area covered by the above-mentioned classes was covered by grasslands and pastures. Generally, they are stored in the workplace, not more than 7.6 thousand hectares. The northern areas (north of the railway) are the largest grazing areas. Ground cover is dominated by grass-gray-yellow and grass-grass soils. Almost a half of the grass gray soils were sank, but less than half the area was dipped.

More than 5.5 hectares - more than 5.5 hectares - the classification from the point of view of the area where the cotton fields dropped. The southern and central-western part of the research object covers mainly grass-gray (grass-gray) grass-grass soils (2 ha). The small area covers anchor-grass-grass (0.7 ha) and gray-black-meadow ( 0.4 hectares).

More than 3.5 hectares occupy wheat fields. Their breaks are 23,659 units. They are available throughout the business, but most of them are in the middle western and northwestern parts. Grass-grass or less in wheat fields - this is the grass-gray light 
soil. Plowed areas are only 0.4 hectares. They are distinguished by gray-grass blond and grass-gray soils for similar reasons. The classification of this category is concentrated in six areas along the main watercourse in the central part of the area, where the average land area (1 ha) is large and the number of fields is 415 .ha.

Covers not more than 1.3 hectares of land. They were equally placed during the settlement period in the settlement. The number of intervals - 10225 . It is found in the southern part of the territory of the large interval, with a segment size of less than 1.5 hectares. These lands are covered with grass-gray and gray-grass, and a small part is covered with gray-yellow grassland lands. In the region of Agsu, relatively small areas of land occupy areas of bushes, trees and vegetation. The general scann (scrap) covers an area of 0.5 hectares and is located in gray-yellow grasslands. They are most commonly found in the south-eastern and central-western parts of a number of research areas.

During the spontaneous heeding period, it is dangerous to remove the plant as a cultivated land, covering 0.4 hectares and more. They are grass-grass soils of grass-gray light soils which are the least. As a result of the study, the analysis of the probability of using the knowledge level about the emergence of the euro in the area, its research methods, the type and usage of gravity information, its layers and descriptions of the scheme attributes, their shape, and the scale and cartographic projections were determined. As the starting material for the creation of the database, the land map characterizing the area: (M 1: 50000); land use map (M 1: 50000); The topographic map (M1: 100000) was taken as a basis. The study investigated the agroecological characteristics of erosion-bearing or erosion hazard rates and the agroecological characteristics of existing soil moisture shortages and the erosion tension in the relief was investigated on the morphological assessment scale.

Based on the findings of the survey, the initial mapping characteristics for the map design are: the number of hills, valleys, steep slopes in the area, the degree of slopes of the slopes, the extent of their spread across the area, the extent of disintegration from the impact of soil and water erosion, and the extent of the sloping soils. Soil erosion's local depth base, etc., has been studied with great depth.

Depending on the map design, the surface sharpness is: 0-30, 3-50, 5-70, 7-100, 10-150, 15-200, 20-250, 25-300, 30-450 and 450 area the average weighted price was taken in the distribution of the May beaker rate and the report was continued with the Zaslavsky formula.

Isr.vzv $=$ - $1 \mathrm{c} 1+$ и2с $2+\ldots . .+$ the insinuation

$$
100
$$

The following abovementioned grants for the design of the Erosion Baseline Depth: 0-50, 5-100, 100-150, 150-200, 200-250, 250-300, 30-400, 400-500 and > 500m are accepted.The exposition maps of the slopes were compiled on a topographic basis and developed on north, north-eastern, north-west, east, south, south- eastern, south-western and western expositions. However, using the soil classification of S.Sobolevin their wash rates were determined. Here, essentially, the compilation of its mail map based on the mathematical model of relief in the territory of Agsu region, which is considered as the main part of the research, has been completed, on which basis the following conclusions are drawn (Figure 1).

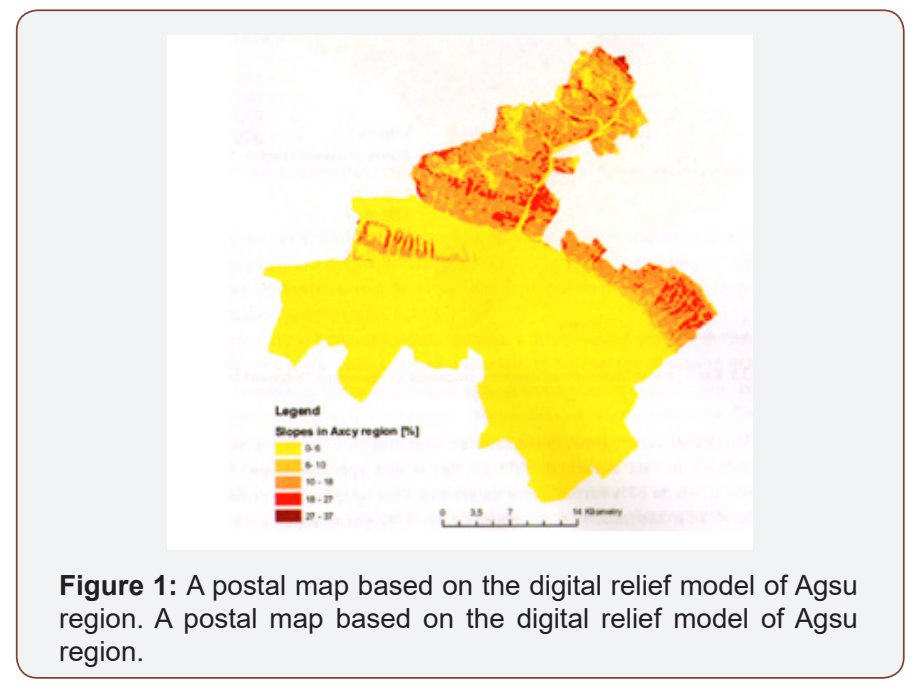

It has been revealed that in the Agsu region, 6\% (3.50\%) mailboxes are located at altitudes of $300 \mathrm{~m}$ above sea level and cover $71 \%$ of the total area. Territories over $6 \%$ are 300 to $1400 \mathrm{~m}$ above sea level and constitute $29 \%$ of the total area.

It should be noted that mailboxes with a score of 6 to 100 are calculated accurately (17\% of the total area) ranging from 10 to $18 \%$.

It was also determined by the study that the distribution for the distribution of the territory corresponds to the following classifications (Table 1).

Table 1: Distribution of land areas by mail class intervals.

\begin{tabular}{|c|c|c|c|c|c|c|c|}
\hline \multirow{2}{*}{$\begin{array}{c}\text { Terri } \\
\text {-tory } \\
\text { Soils }\end{array}$} & \multicolumn{5}{|c|}{ Class Interval slope \%-with } & \\
\cline { 2 - 8 } & $\mathbf{0 - 6}$ & $\mathbf{6 - 1 0}$ & $\mathbf{1 0 - 1 8}$ & $\mathbf{1 8 - 2 7}$ & $\mathbf{2 7 - 3 5}$ & $\mathbf{> 3 5}$ & Total \\
\hline$\underline{\text { ha }}$ & $\underline{71131}$ & $\underline{\mathbf{7 3 9 3}}$ & $\underline{17033}$ & $\underline{4326}$ & $\underline{164}$ & $\underline{0}$ & $\underline{\underline{100047}}$ \\
\%- with & $71,1 \%$ & $7,39 \%$ & $17,02 \%$ & $4,32 \%$ & $0,16 \%$ & 0 & $\begin{array}{c}99,99 \\
\%\end{array}$ \\
\hline
\end{tabular}

The geographical informational system reflects the creation of a cartographic material based on the database created for this electronic map for the use of land on the territory of Agsu region for thematic research layer. From this point of view, it is achieved by collecting the data collected by means of working software packages for the machine that has been developed for a specific purpose, and the corresponding drawback is achieved. which is followed by accurate measurements.

a. The analysis of the structure of the land use in the Aghsu region shows once more that the territory of the region is really agricultural. Thus, land plots in the region are over 50\% of the total land area and found that grasslands, steppes and degraded desertification areas constitute $23 \%$ of the total area. Additionally, in addition to the agricultural lands of the district, 
$3 \%$ of the land, garden, gardens, vineyards and so on. completes itself with.

b. It is known that forest and bushes are small in the area and constitute up to $12 \%$ of the total area. It has also been discovered that there are areas in the region that are completely covered by vegetation and constitute $4 \%$ of the total area.

c. A small part of the area is characterized by ponds, wetlands, urban and rural construction areas, accounting for $6.9 \%$ of the total area.

d. From the analysis of the results of the research, it is concluded that most of the agricultural land is located at altitudes of $400 \mathrm{~m}$ above sea level.

e. Only the grasslands conquer the lands of the $1400 \mathrm{~m}$ height.

f. Other forms of land use are observed at lower altitudes.

Research on the determination of slopes' mails revealed that most of the area is located in the mail class of $0-6 \%$, and the mail rate is 3.50 , which is $71 \%$. Only the grassland, the green massive and the broader wooded forests are higher located on the hilly slopes. All of the reporting material will be developed for the purpose of using the land in the region and will be solved at other stages of the research, which will be further explored in the future as well as on base material. At present, the composition of the soil cover and the determination of the durability of the soil cover are being investigated so that it has become apparent that a large proportion of them in species varieties, $26 \%$ of the total area, gray soils of the gray grass soils and $12 \%$ of the total area and about $11 \%$ of the total land area. An analysis of the preliminary data analysis conducted on known research assignments makes it evident that the majority of the area is resistant to leakage and the total territorial lands is $58 \%$ of the total and relates to the first degree of leakage. The areas belonging to the 3 rd degree of sustainability is $28.5 \%$ of the total area. Later, more and more non-fertile soils were found to be only $1.6 \%$ in the area. In order to create a database, the work on the mapping of land use maps and topographic map of 1: 50000 scale is underway (Figure 2).

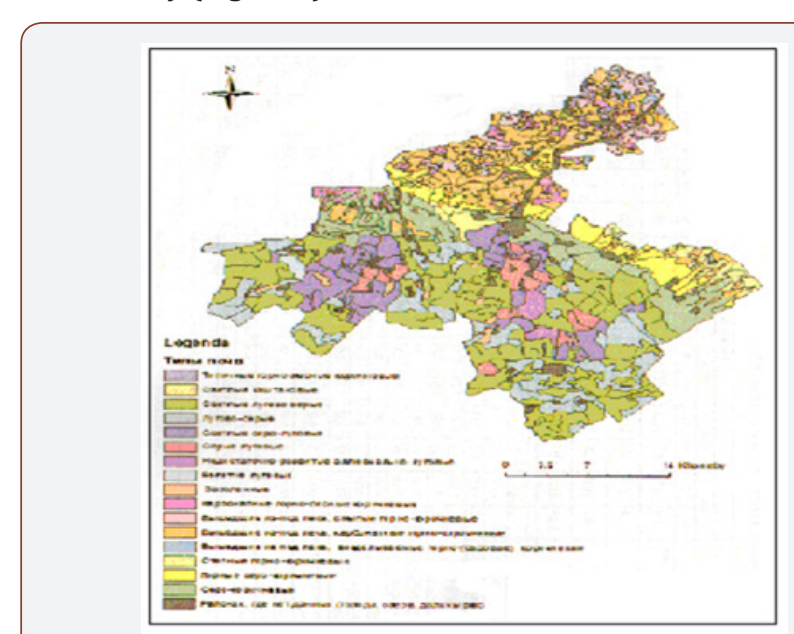

Figure 2: Agsu region's land map.
At the same time, a raster-format relief model is developed with a 90 m extension (Figure 3).

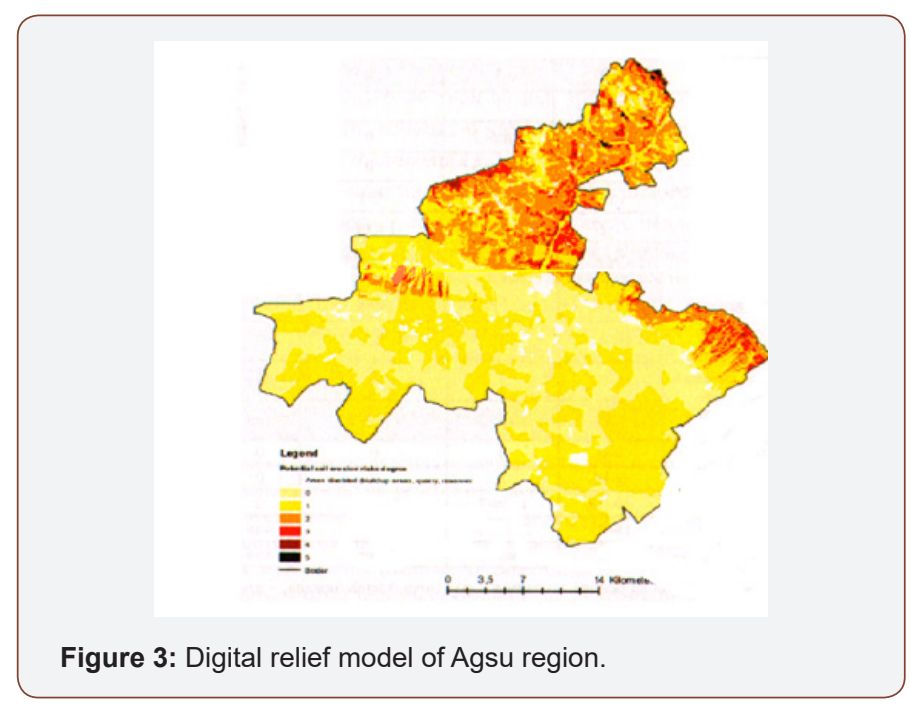

It should be noted that, based on the findings of the research, it is recommended to investigate the dissemination of erosion processes and the measures to be taken against it (Figure 4).

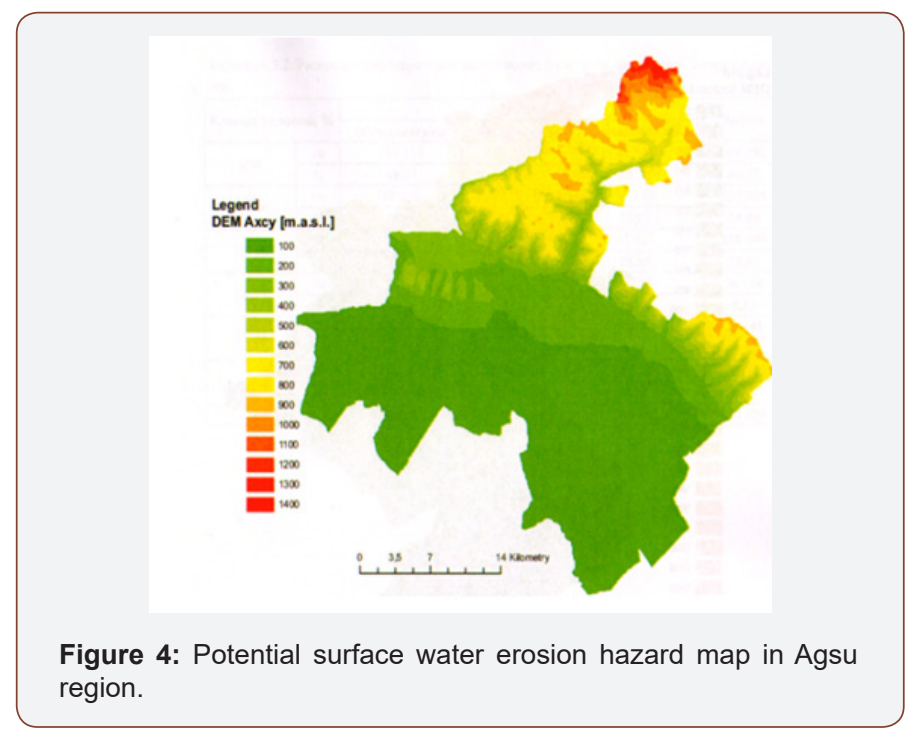

Based on the acquired primary materials: erosion process; Thanks to the organization of scientific knowledge on the erosion process and its analysis methods, the following thematic layers have been developed. Including:

- $\quad$ digital relief model in -rastr format;

- $\quad$ terrain-type in rastrous format;

- $\quad$ land vector format;

- $\quad$ use of voracious arrays;

The collected material is included in the data base of the aforementioned soil layer, and then, due to the projection and scale of the initial data, they have been assigned a single scale and projection, the scale of the map is 1: 100000, and the projection Pulkova 1942_GK_zona 13 [25-29]. 


\section{Results}

1. Determination of the most efficient and progressive ways of using natural resources in the economic geographical region of Mountainous Shirvan, using them economically and so on. such issues are very urgent, and in this regard, there is a great need for extensive scientific research on the area of detection, learning and re-evaluation of natural resources. This will help to further improve the region's economy and improve the living standards of the population through the solution of problems.

2. On the basis of the economic geographical region of Nagorno-Shirvan, the agrarian-industrial enterprises, electrical engineering, carpentry, forestry and woodworking, building materials production are in line with the requirements of the day and are actual.

3. In the research area, besides the development of agriculture, the ecological issues should also be considered. Soil, water, plant, animal world and so on. the protection of natural resources and the efficient use of them are among the top priority issues in this area. From this point of view, land reclamation measures, preventing forests breakage, strict protection of endangered species of plants and animals, and so on. such actions are very actual.

4. Low level of water availability in the region, low and medium flow of water in the region, creating small amounts of closed water in slopes, as well as the use of collected water resources for irrigation during the hot period of the year, improving existing irrigation systems, there is a great need for the establishment of irrigation facilities and drilling of artesian wells.

5. Taking into account that there are many natural and anthropogenic recreation resources in both the mountainous and plain areas in the region, the development prospects for the development of the service sector and other infrastructural areas meeting modern requirements are factors that can have a major impact on the socio-economic development of the region, The reconstruction work would be beneficial to the development of hydrocarbon production along with other farming areas.

6. It is decided that such an assumption would be made in the initial data analysis of studies. The majority of the area is resistant to washing. The analysis of the structure of the land use in the Agsu region is once again proven that, in fact, the land areas of the common land, including the lands of the region, are of agricultural importance.

7. The geographical informative system reflects the usefulness of the cartographic materials obtained on the basis of the data base for the preparation of an electronic map for the use of land in the Aghsu region for the specific research layer. In this regard, it is recommended to investigate and disseminate the erosion process in the area and the available methods of combating it.

\section{Acknowledgement}

None.

\section{Conflict of Interest}

No conflict of interest.

\section{References}

1. Aliyev GA (1994) Greater Caucasus. Baku 232.

2. Abbasov CP (1998) Economic and social geography of Azerbaijan. Baku 263.

3. (2006) Regional Geographic Problems of the Republic of Azerbaijan. (On Guba-Khachmaz economic region) Baku 156

4. (1996) Azerbaijan's constructive geography. Baku 3: 236.

5. (2008) Statistical indicators of Azerbaijan. Baku 521.

6. (1986) Babazade BM Scion and non-ore minerals. Baku 109.

7. Budagov BA (1974) Natural landscapes of Azerbaijan SSR and their protection. Baku 156.

8. Budagov BA (1988) The natural landscapes of Soviet Azerbaijan. Baku 230.

9. Budagov BA (1969) Geomorphology of the Greater Caucasus Baku 356.

10. Budagov BA (1990) Natural phenomena of Azerbaijan. Baku 208.

11. Guliyev VO (1984) The plant world of Azerbaijan and its protection. Baku 312.

12. Eyyubov AK (1993) Agroclimatic atlas of the Azerbaijan Republic. Baku 19.

13. Eyyubov A.K. Climate resources of the Azerbaijan SSR. Baku, 1984, 26 p.

14. Alekperov KA (1961) Land erosion and struggle with it in Azerbaijan. Baku 189.

15. (1983) Alasgarov AK Economic regions and their transport system. Baku 235.

16. Alirzayev AQ (1999) Azerbaijan's development concept and program. Baku 227.

17. Alirzayev AT (1987) Socio-economic problems of the village. Baku 105.

18. Aliyev HA (1964) The forest and forests of the Greater Caucasus. Baku 161.

19. Askerov AH (1966) Mineral waters of Azerbaijan. Baku 66.

20. Asgarov AC (1989) Environmental protection. Baku 124.

21. (2008) Information from the Ministry of Agriculture. Baku 135

22. Sub AA Madatzade, E Schuhlinsky (1968) Climate in Azerbaijan. Baku 56.

23. Musseyibov MM (1999) Physical geography of Azerbaijan. Baku 325.

24. Museibov MA (1981) Landscape of the Azerbaijan SSR. Baku 163.

25. Priilippo LI (1970) Vegetation cover of Azerbaijan. Baku 203.

26. Rustamov SH, Qashqay RM (1989) Water resources of the Azerbaijan SSR. Baku 235.

27. Rustamov SG (1960) Reiki of the Azerbaijan SSR and their hydrological excellence. Baku.

28. Rustamov SG (1960) Hydrological district of Azerbaijan. Baku 256.

29. Rustamov SG, Kashgay RM (1978) Water balance The Azerbaijani SSR. Baku 218 